\title{
A Vision for the Future: Innovations in Care for Older Adults in the Netherlands
}

\author{
By Hugo de Jonge
}

\section{Today, Dutch people are living longer, healthier lives than ever before. Currently, there are 1.3 million people over 75 years old in the Netherlands, out of a population of more than 17 million.}

By 2030, that number will have risen to 2.1 million (see chart on page 74: Senior Population Index: the Netherlands 1970-2018). This growing population of older people has a wide range of needs, and the government's aim is for society to accommodate these needs through innovative and pragmatic solutions that challenge outmoded ideas about the "sunset of life." This vision did not develop overnight; it evolved from a long tradition of care for older adults in the Netherlands. In previous decades, this care was usually standardized in large-scale institutions. The current approach is increasingly personalized. This modernized vision is one of the pillars of the "Growing Old with Dignity" manifesto, to which the current government committed itself in its coalition agreement. The manifesto pledges support to people who are living longer, and calls for helping people live gratifying lives into old age.

Older adults are a vital part of our nation's future and make many valuable contributions to society. I strongly believe that one is never too old to participate. It is important that society appreciates and recognizes the capacities and contributions of our older citizens and offer them the care and support they deserve. To this end, I formed a Pact on Care for Older Adults in March 2018 with various civil society organizations, social enterprises, companies, and ANBO, the Dutch advocacy group for older people. Together we will work to improve care for and support to older citizens at the regional, local, and neighborhood levels. By now, over 170 organizations have signed the pact, which introduced three interconnected programs: Aging in Place (focused on better-quality care at home and developing new types of housing), Nursing Home Care (focused on improving the quality of nursing home care), and United Against Loneliness (focused on reducing loneliness and social isolation among older adults). These programs are described in detail below.

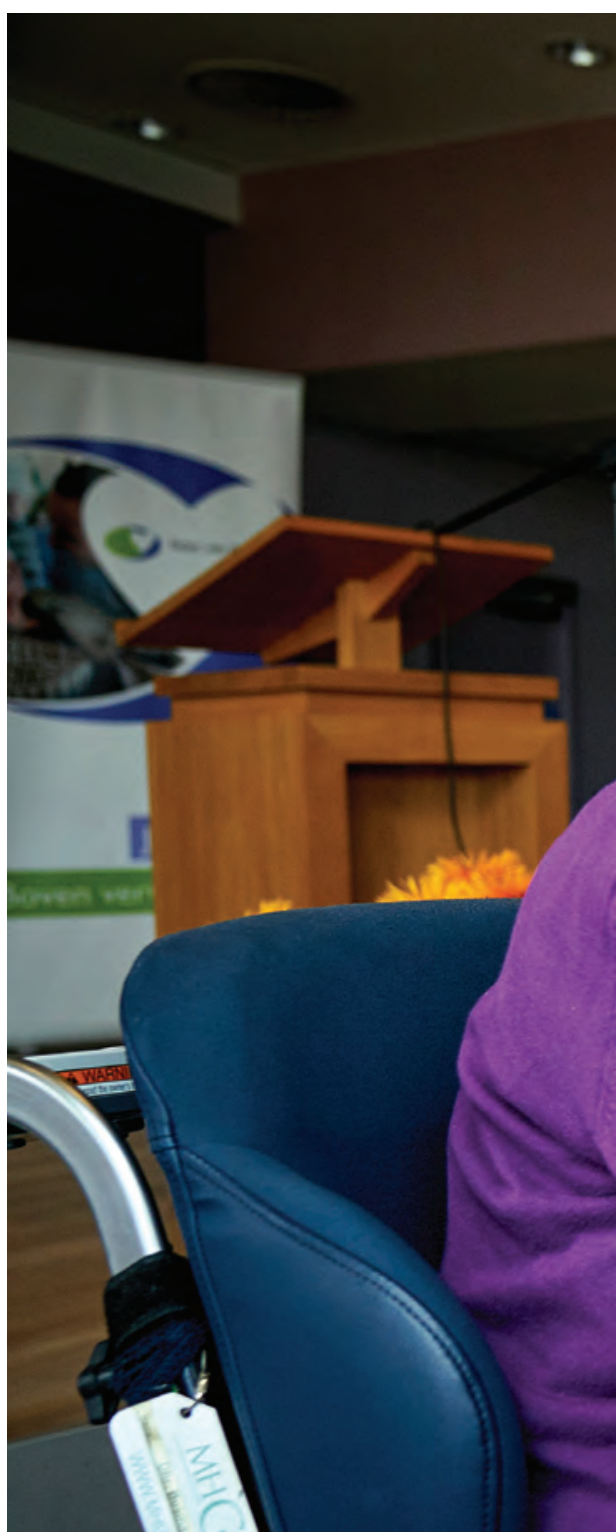




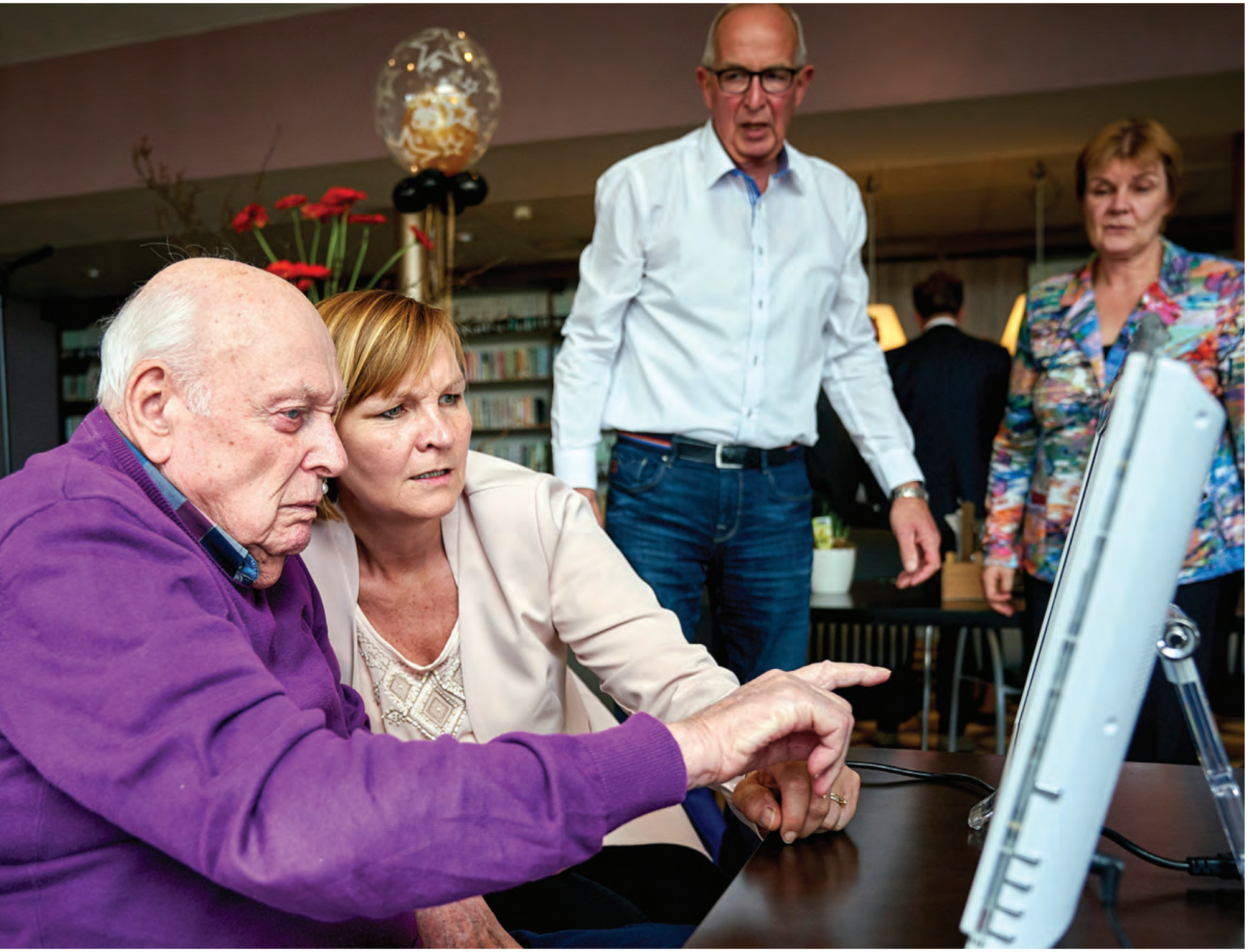

Familiarizing seniors with E-health.

\section{Aging in Place}

Aging in place is increasingly common: 92 percent of people ages 75 and older currently live at home, as do 67 percent of people over 90 . Often, these are the places where people have spent a large part of their lives, where they raised their children, where they made memories, and where every nook and cranny is familiar. It is only natural that people want to grow old there. One goal of the program is therefore to ensure that older people get the care they need so they can keep living at home. Nearly a quarter of people over 75 need assistance from informal caregivers such as family, friends, or volunteers, and care professionals like GPs, district nurses, and social workers. However, the number of people who can provide this assistance will decline with our aging population. It is therefore important that we develop new forms of respite care and personalized support for informal caregivers.
E-health enables more personalized care and support. Smart sensors, such as medicine dispensers that monitor medicine use, and powerful analytics for remote lifestyle monitoring, such as keyless entry systems and location devices for people with dementia who wander, are valuable tools. They help (informal) caregivers identify changes in older people's daily living patterns, offer detailed insights into their well-being, and facilitate communication among the various carers and the person being cared for. As a result, care provides can offer round-the-clock customized and preventive home care, allowing people (including those with dementia) to age in place with dignity.

In addition to personalized support, home adaptations, or access to suitable amenities, the Aging in Place program focuses on what older adults can do themselves. Establishing what someone wants or needs as they grow older and how to achieve these wishes 


\section{Senior Population Index: the Netherlands 1970-2018}

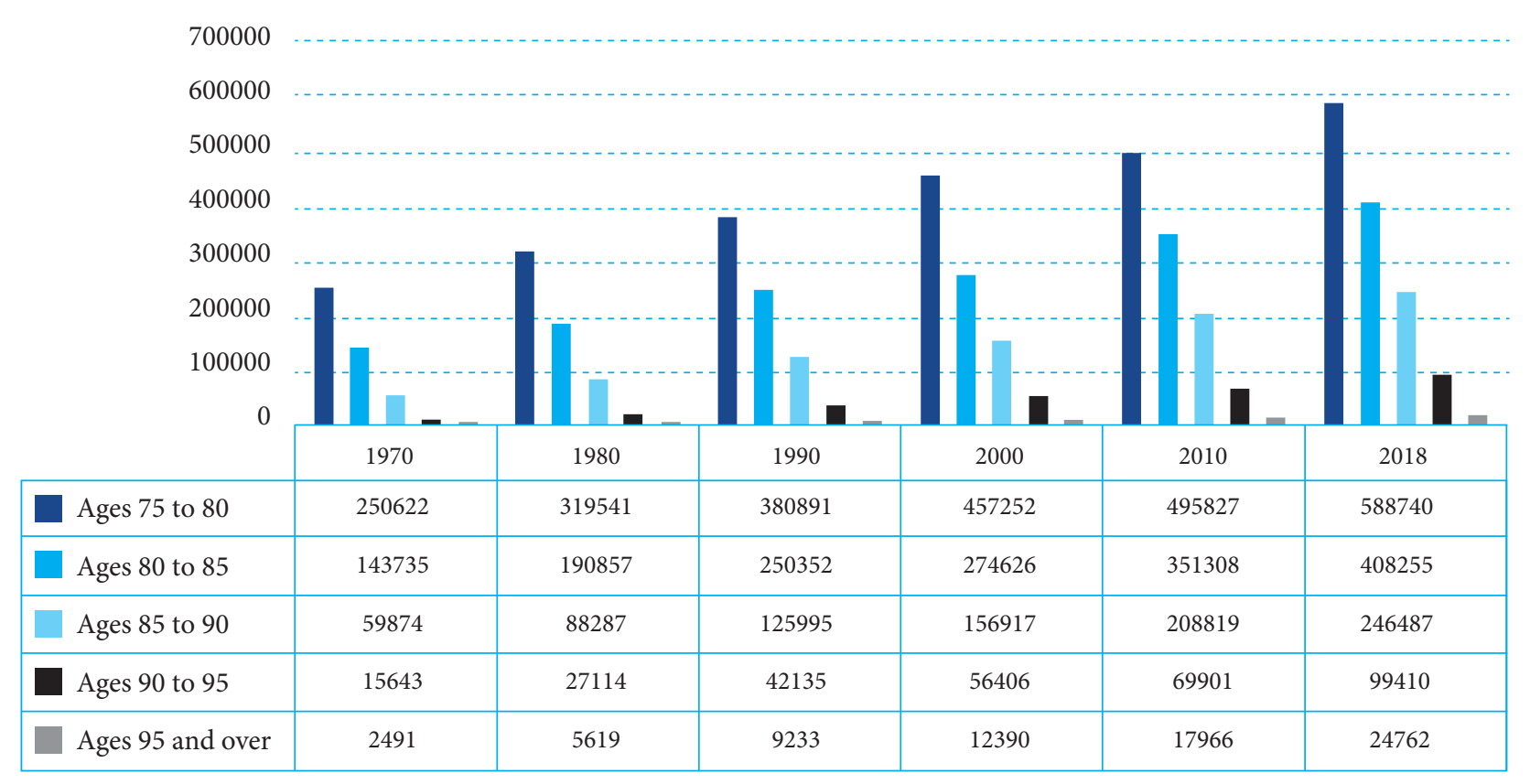

is a vital component of aging with dignity. The sooner people start the conversation about how they see their future, the more care and support can be tailored to them.

\section{Nursing Home Care}

Even with the best possible care arrangements and home adaptations, there comes a point for some people when living at home becomes infeasible. Their environment is no longer suitable for their situation. When a home starts to feel too confining, housing that is intermediate between one's own home and residential care can be a viable alternative. Together with municipalities and housing associations, the government is developing strategies to create small-scale "in-between" housing for older people that offers personalized care and support as well as semi-independent living and self-reliance at the community level.

While e-health solutions offer many benefits, personal contact remains incredibly important, especially for older adults who have become forgetful and socially isolated. With this in mind, a number of intergenerational living facilities have been set up where students and older people live in the same building. The social return on investment in such facilities is that they combat loneliness in both generations.
One of the first innovative living models set up exclusively for older adults was Hogeweyk. Established in 2012, Hogeweyk was built as an entirely self-contained neighborhood with shops, restaurants, cafés, and detached homes. Each home accommodates six older adults with advanced dementia. Unlike in many facilities, residents can move about freely in Hogeweyk and live as much of a normal life as possible. In recent years, Hogeweyk has inspired numerous care farms around the country catering to people with dementia. Some farms offer daytime activities to older people living at home, while others offer long-term residential care in small communities.

Studies show that care farms give people with dementia a sense of purpose, help them regain their self-worth, and allow them to practice useful skills. The farms also reduce social isolation, provide respite to informal carers, and offer a safe and stable setting where people can function semi-independently. Ultimately, this type of specialized care lowers the need for medication, slows down the progression of dementia, and enables aging in place. Effective and innovative approaches such as this hold great promise for the future. 


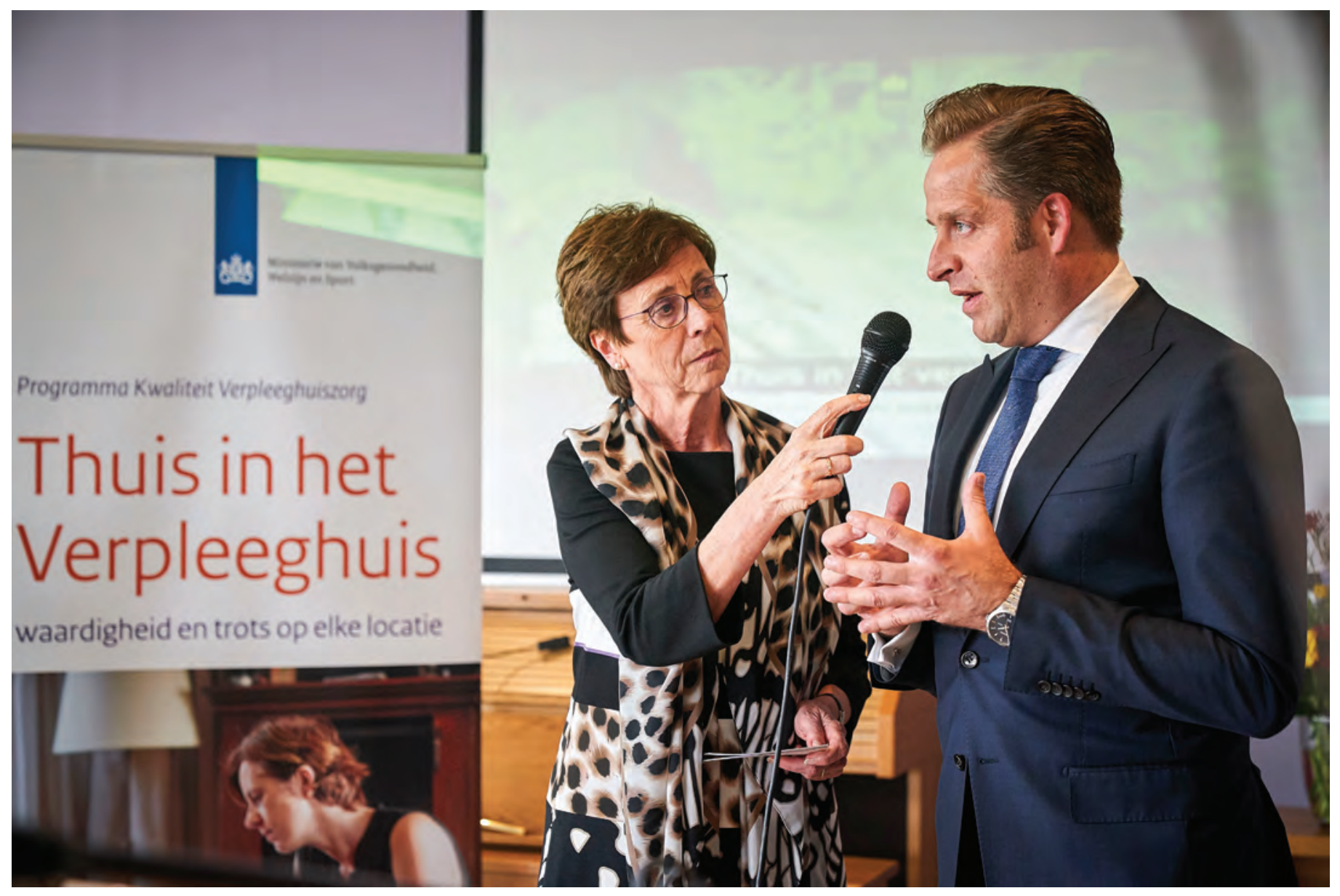

"A number of intergenerational living Presentation on Nursing Home Care. facilities have been set up where students and older people live in the same building. The social return on investment in such facilities is that they combat loneliness in both generations."

The current trend of aging in place and the growing need for "in-between" residences and innovative living models is reflected by the steady decline of permanent nursing home residents: from 16 percent of the population over 75 in 1995 to 8 percent in 2018. In 2015, 32 percent of people ages 90 and older lived in a care home or nursing home. In 2035, this will be less than 20 percent.

Nevertheless, moving to a nursing home sometimes becomes inevitable. For the people in question, it is often a difficult decision that involves a sense of loss and taking leave of loved ones. In order to make this transition easier, the standard of nursing home care should be measurably and tangibly improved. Therefore, the question "Would I or my parents want to grow old here?" should be on the minds of all care providers. The new Quality Framework for Nursing Home Care allows older people and their loved ones to better answer this question and make well-informed choices. It not only monitors quality, but also sets strict standards and facilitates the exchange of knowledge and best practices. As a result, nursing home care is steadily becoming more and more personalized.

Personalized care allows older adults to retain a sense of independence and freedom of choice on matters such as deciding when and what to eat, whether to go out for a walk (with a companion), what TV program to watch, or what activities to engage in. It is also important that people have an established group of caregivers because this provides a sense of continuity and stability and promotes trust. Actively involving family members in care and decision making is also key in achieving custom-made care and enabling older adults to age with dignity. 


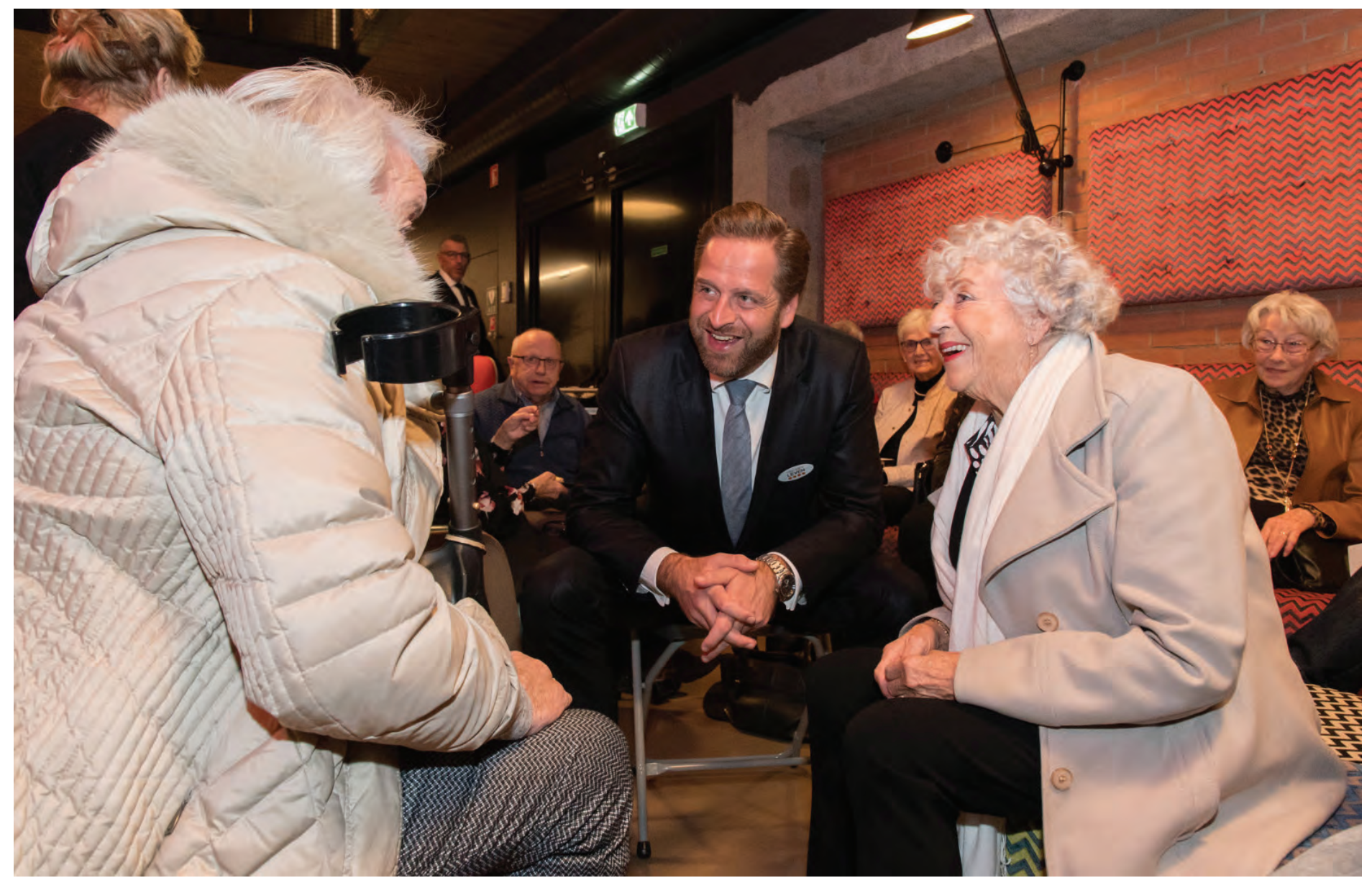

Socially isolated older adults converse with Secretary de Jonge while attending the theater production of Charley the Musical. The older people are accompanied by their peers and guided by volunteers who initiated the visit under the auspices of the United Against Loneliness program.

\section{"I will initiate a campaign in spring 2019 - in consultation with older adults themselves - that addresses the meaning of aging and its place in today's society."}

United Against Loneliness

The third program announced in the Pact on Care for Older Adults focuses on combating social isolation and loneliness. Half of all people over 75 in the Netherlands reported feelings of loneliness. This means there are 700.000 older adults who are socially isolated. Without immediate action, their number will increase to 1 million by 2030 . While social isolation may be typical of our times, that does not mean we should accept it. Who wants to live in a society that leaves you to your own devices?

Loneliness is such a large and complex issue that it can have a paralyzing effect. We cannot expect loneliness to be eradicated entirely, but we can ask people to combat social isolation on an individual basis. The Ministry of Health, Welfare and Sport has developed a website that informs people how they can recognize the signs of loneliness, where to report it, and how to help combat it, for instance by joining neighborhood initiatives. Anyone can decide to become a better neighbor today and make someone else feel that the world cares. Taking care of each other should once more be generally expected. This requires a customized approach that is mindful of the differences between urban and rural areas. To this end, a number of cities in the Netherlands have joined the World Health Organization's Global Network for Age-Friendly 


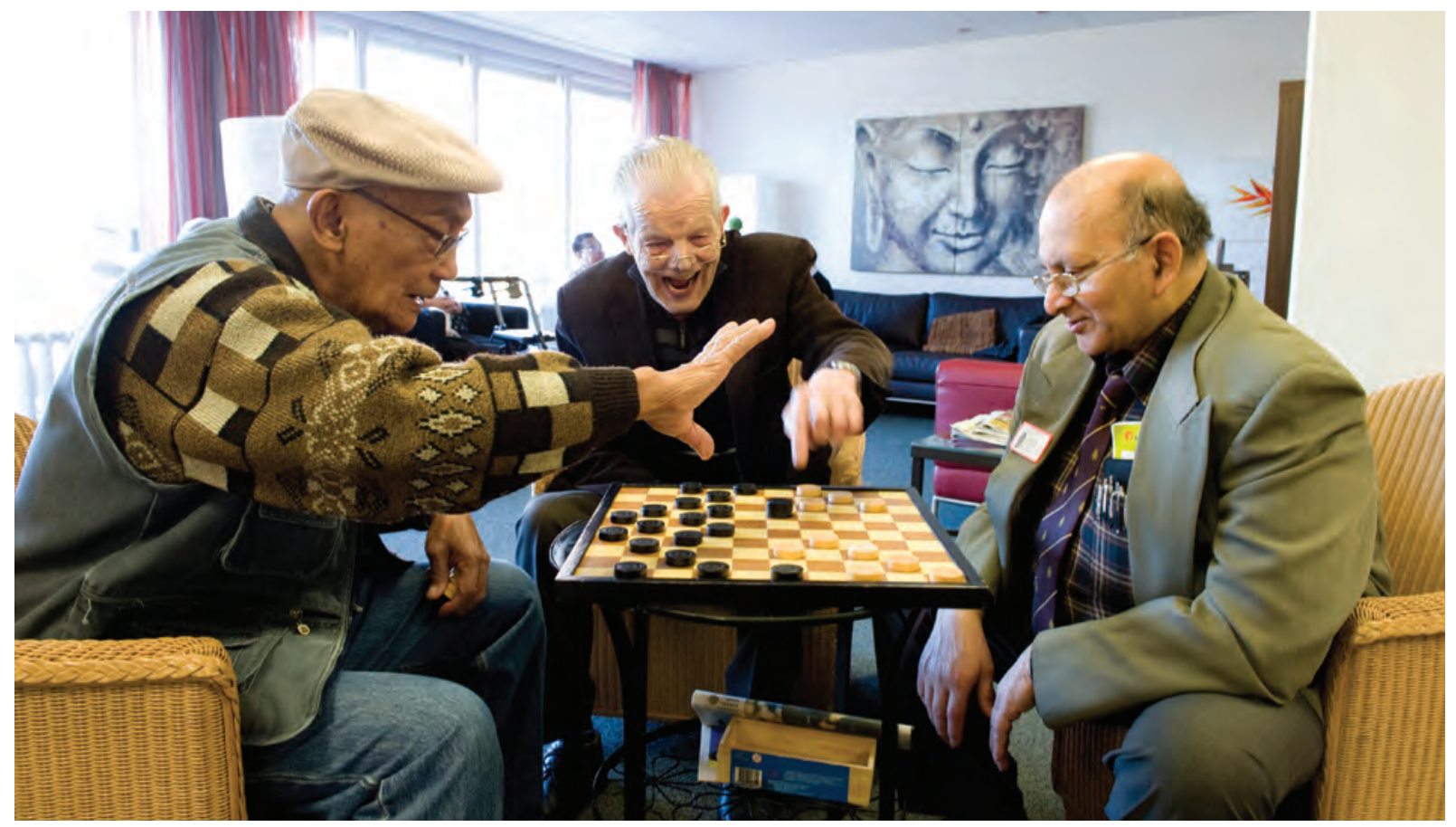

FEATURE

Seniors participating in activities of choice.

Cities and Communities. Together with network partners, participating cities encourage active aging in urban environments by promoting security and creating opportunities for healthy activities and social and cultural participation. I am confident that together with the existing nationwide coalition, we can combat loneliness among older people.

\section{Renewed Appreciation of Older Adults}

As I mentioned above, more older adults are participating in society, and they are more vital than ever. They have paid jobs, look after their grandchildren, do volunteer work, and perform a range of other tasks. They can also share a lifetime of experience with younger generations. In order to inspire fresh and contemporary perceptions of older people, I will initiate a campaign in spring 2019 - in consultation with older adults themselves - that addresses the meaning of aging and its place in today's society. The campaign is aimed at renewing appreciation of older adults by emphasizing their strength and wisdom.

Finally, in order to fully understand the vision underpinning the Netherlands' current policy on care for older adults, it is vital to consider its historical context, the principles on which it is based, and the social developments that have helped shape this policy. I am pleased that this special feature offers readers insight into the Dutch approach to care for older adults and enables them to examine aging in the Netherlands from a governmental and civil society perspective.

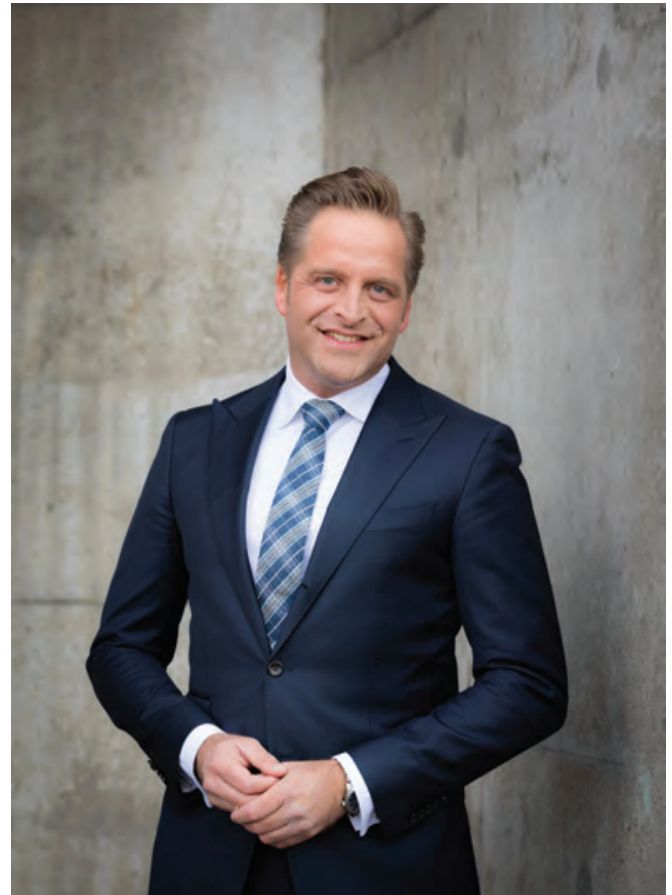

Hugo de Jonge

DEPUTY PRIME MINISTER,

MINISTER OF HEALTH, WELFARE AND SPORT

THE NETHERLANDS 